\title{
Evidence for a Proton-Protein Symport Mechanism in the Anthrax Toxin Channel
}

\section{Citation}

Basilio, Daniel, Stephen J. Juris, R. John Collier, and Alan Finkelstein. 2009. Evidence for a proton-protein symport mechanism in the anthrax toxin channel. Journal of General Physiology 133(3): 307-314.

\section{Published Version}

doi:10.1085/jgp.200810170

\section{Permanent link}

http://nrs.harvard.edu/urn-3:HUL.InstRepos:8347340

\section{Terms of Use}

This article was downloaded from Harvard University's DASH repository, and is made available under the terms and conditions applicable to Other Posted Material, as set forth at http:// nrs.harvard.edu/urn-3:HUL.InstRepos:dash.current.terms-of-use\#LAA

\section{Share Your Story}

The Harvard community has made this article openly available.

Please share how this access benefits you. Submit a story.

\section{Accessibility}




\title{
Evidence for a Proton-Protein Symport Mechanism in the Anthrax Toxin Channel
}

\author{
Daniel Basilio, ${ }^{1}$ Stephen J. Juris, ${ }^{2}$ R. John Collier, ${ }^{2}$ and Alan Finkelstein ${ }^{1}$ \\ ${ }^{1}$ Department of Physiology and Biophysics, and Department of Neuroscience, Albert Einstein College of Medicine, \\ Bronx, NY 10461 \\ ${ }^{2}$ Department of Microbiology and Molecular Genetics, Harvard Medical School, Boston, MA 02115
}

\begin{abstract}
The toxin produced by Bacillus anthracis, the causative agent of anthrax, is composed of three proteins: a translocase heptameric channel, $\left(\mathrm{PA}_{63}\right)_{7}$, formed from protective antigen $(\mathrm{PA})$, which allows the other two proteins, lethal and edema factors (LF and EF), to translocate across a host cell's endosomal membrane, disrupting cellular homeostasis. It has been shown that $\left(\mathrm{PA}_{63}\right)_{7}$ incorporated into planar phospholipid bilayer membranes forms a channel capable of transporting LF and EF. Protein translocation through the channel is driven by a proton electrochemical potential gradient on a time scale of seconds. A paradoxical aspect of this is that although $\mathrm{LF}_{\mathrm{N}}($ the N-terminal 263 residues of LF), on which most of our experiments were performed, has a net negative charge, it is driven through the channel by a cis-positive voltage. We have explained this by claiming that the $\left(\mathrm{PA}_{63}\right)_{7}$ channel strongly disfavors the entry of negatively charged residues on proteins to be translocated, and hence the aspartates and glutamates on $\mathrm{LF}_{\mathrm{N}}$ enter protonated (i.e., neutralized). Therefore, the translocated species is positively charged. Upon exiting the channel, the protons that were picked up from the cis solution are released into the trans solution, thereby making this a proton-protein symporter. Here, we provide further evidence of such a mechanism by showing that if only one $\mathrm{SO}_{3}{ }^{-}$, which is essentially not titratable, is introduced at most positions in $\mathrm{LF}_{\mathrm{N}}$, through the reaction of an introduced cysteine residue at those positions with 2-sulfonato-ethyl-methanethiosulfonate, voltage-driven $\mathrm{LF}_{\mathrm{N}}$ translocation is drastically inhibited. We also find that a site that disfavors the entry of negatively charged residues into the $\left(\mathrm{PA}_{63}\right)_{7}$ channel resides at or near its $\Phi$-clamp, the ring of seven phenylalanines near the channel's entrance.
\end{abstract}

\section{INTRODUCTION}

The toxin produced by Bacillus anthracis, the causative agent of anthrax, has proved to be a promising model system to study the molecular driving forces that govern protein translocation across biological membranes. It is composed of three separate monomeric proteins: protective antigen (PA; $83 \mathrm{kD})$, named for its effectiveness in inducing protective antibody-mediated immunity against anthrax, and two enzymes, lethal factor (LF; $90 \mathrm{kD})$ and edema factor (EF; $89 \mathrm{kD})$. The three proteins may be produced recombinantly in soluble form and studied independently (for a review of anthrax toxin see Young and Collier, 2007). Toxin action is initiated by a self-assembly process. First, PA binds to a cell surface receptor, where it is activated by a furin family protease that cleaves off a $20-\mathrm{kD}$ N-terminal fragment. The remaining $63-\mathrm{kD}$ receptor-bound portion $\left(\mathrm{PA}_{63}\right)$ self-assembles into a ring-shaped homoheptamer, called

D. Basilio and S.J. Juris contributed equally to this work.

Correspondence to Daniel Basilio: dbseyler@aecom.yu.edu

S.J. Juris's present address is Depts. of Biology and Chemistry, Central Michigan University, Mount Pleasant, MI 48859.

Abbreviations used in this paper: EF, edema factor; LF, lethal factor; MTS-ACE, 2-aminocarbonyl-ethyl-methanethiosulfonate; MTS-ES, 2-sulfonato-ethyl-methanethiosulfonate; MTS-ET, 2-trimethylammonium-ethylmethanethiosulfonate; PA, protective antigen; PEG, polyethylene-glycol; WT, wild-type. the prepore. The prepore may then form complexes with up to three molecules of EF and/or LF. These complexes are endocytosed and delivered to an acidic vesicle compartment, where the prepore undergoes an acidic $\mathrm{pH}$-dependent conformational rearrangement to form a cation-selective, ion-conducting channel. The $\left(\mathrm{PA}_{63}\right)_{7}$ channel spans the membrane as an extended, 14-stranded $\beta$ barrel (Benson et al., 1998; Nassi et al., 2002; Nguyen, 2004; Katayama et al., 2008) that serves as the conduit for LF and EF into the cytosol. Once in the cytosol, $\mathrm{LF}$, a $\mathrm{Zn}^{2+}$ protease, specifically cleaves and inactivates MAP kinase kinases (Pannifer et al., 2001), and $\mathrm{EF}$, a $\mathrm{Ca}^{2+}$ calmodulin-dependent adenylyl cyclase, increases cAMP levels (Drum et al., 2002); both activities benefit invading $B$. anthracis by suppressing the host's immune functions (Young and Collier, 2007).

A model of the $\left(\mathrm{PA}_{63}\right)_{7}$ 14-strand $\beta$ barrel reveals that its lumen is $\sim 15$ - $\AA$ wide and is able to accommodate secondary structure only as large as an $\alpha$-helix (Krantz et al., 2004). Translocation through the lumen thus requires the substrates to unfold. Thermodynamic analysis

(C) 2009 Basilio et al. This article is distributed under the terms of an Attribution-Noncommercial-Share Alike-No Mirror Sites license for the first six months after the publication date (see http://www.jgp.org/misc/terms.shtml). After six months it is available under a Creative Commons License (Attribution-Noncommercial-Share Alike 3.0 Unported license, as described at http://creativecommons.org/licenses/by-nc-sa/3.0/). 
of the conformational stabilities of the homologous $\sim 250$-residue amino-terminal domains of LF and EF $\left(\mathrm{LF}_{\mathrm{N}}\right.$ and $\mathrm{EF}_{\mathrm{N}}$, respectively) indicates that acidic conditions encountered in the endosome are sufficient to destabilize the native structures of these proteins (Krantz et al., 2004). When added to planar lipid bilayer membranes, $\left(\mathrm{PA}_{63}\right)_{7}$ forms channels with a unitary conductance of $\sim 55 \mathrm{pS}$ in $100 \mathrm{mM} \mathrm{KCl}$ at pH 5.5 (Krantz et al., 2005); at pM concentrations, several thousand channels can be incorporated into the membrane (Blaustein et al., 1989). It has been demonstrated that these channels are capable of translocating LF and EF across planar lipid bilayers (Krantz et al., 2006), where the amino terminus precedes the carboxy terminus into the pore (Zhang et al., 2004a), and the driving force comes from the gradient of the electrochemical potential of $\mathrm{H}^{+}$ (Zhang et al., 2004b; Krantz et al., 2006). However, translocation is more complicated than acid-induced unfolding, followed by electrophoresis through a passive pore (Finkelstein, 2009). Both the second law of thermodynamics and the laws of electrostatics require that the translocated species have a net positive charge, given that a cis-positive voltage drives translocation, yet $\mathrm{LF}_{\mathrm{N}}$ has a net negative charge. $\left(\mathrm{LF}_{\mathrm{N}}\right.$ contains 54 acidic side chains [19 aspartates and 35 glutamates] and 47 basic side chains [ 5 arginines, 9 histidines, and 33 ly- sines] [Bragg and Robertson, 1989]. If the pKs of the side chains are the same as those of their respective free amino acids, $\mathrm{LF}_{\mathrm{N}}$ bears a net negative charge of $\sim-7$ at pH 5.5 and $\sim-12$ at pH 6.5, a symmetric pH at which $\mathrm{LF}_{\mathrm{N}}$ translocation can still be driven by voltage [Krantz et al., 2006]. Thus, unless the average pKs of the aspartates and glutamates on $\mathrm{LF}_{\mathrm{N}}$ are shifted 1.5 units or more above their free amino acid values, $\mathrm{LF}_{\mathrm{N}}$ bears a net negative charge at at least some of the pHs at which its translocation has been studied.) The simplest mechanism to achieve a positive charge on the translocated species is for the carboxyl groups of the aspartic and glutamic acid residues to be largely neutralized, i.e., protonated. Thus, these carboxyls on $\mathrm{LF}_{\mathrm{N}}$ must pick up protons from the cis solution at some point during their entrance into the channel, and then discharge them into the trans solution as they exit the channel. In other words, the $\left(\mathrm{PA}_{63}\right)_{7}$ channel functions as a proton-protein symporter (Krantz et al., 2006; Finkelstein, 2009). At all times, the portion of $\mathrm{LF}_{\mathrm{N}}$ that lies within the channel bears a net positive charge.

At pH 5.5, a carboxyl on $\mathrm{LF}_{\mathrm{N}}$ spends $\sim 97 \%$ of its time in its ionized, negatively charged form (assuming the pKs of the aspartates and glutamates on $\mathrm{LF}_{\mathrm{N}}$ are approximately the same as those of the free amino acids). Why, then, should its minority, protonated neutral form be

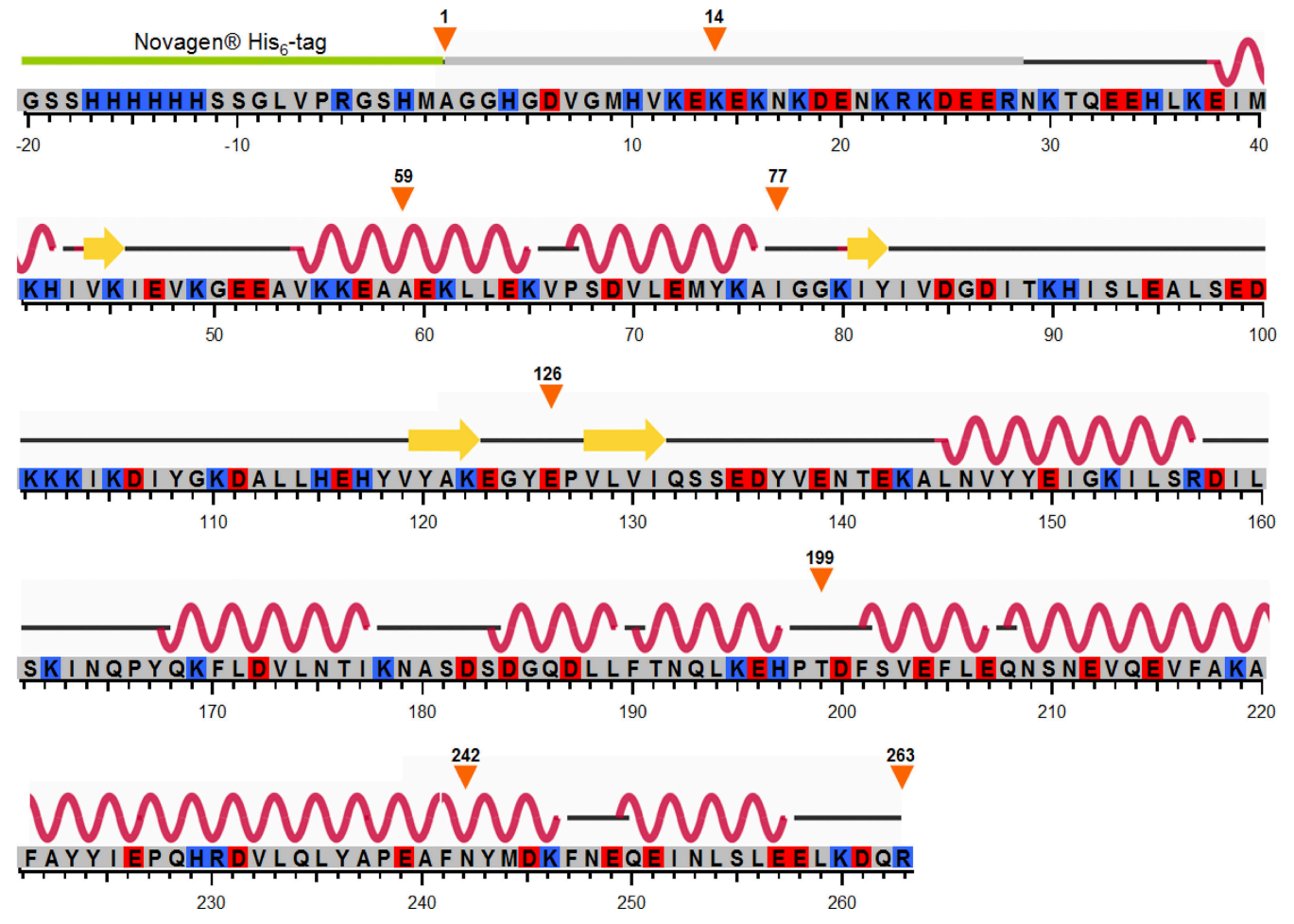

Figure 1. The primary sequence of $\mathrm{LF}_{\mathrm{N}}$ (Bragg and Robertson, 1989) with its N-terminal Novagen His $6_{6}$-tag. The orange arrows mark the cysteine mutants investigated in this paper. Acidic residues (aspartates and glutamates) are colored in red, and basic residues (lysines, arginines, and histidines) are in blue. Above the sequence, the red sine waves designate $\alpha$-helices, the yellow arrows are $\beta$-structure, the black lines mark neither $\alpha$-helices nor $\beta$-structure, as determined from the crystal structure of LF (PDB entry 1JKY), and the gray line designates the unresolved unstructured region, residues 1-28. 
the one that enters the channel? It can be argued that the channel's significant (although not ideal [Blaustein et al., 1989; Blaustein and Finkelstein, 1990]) cation selectivity implies that it strongly disfavors entry of negatively charged side chains into the channel. Here, we provide further evidence for the importance of the protonation of the carboxyls on $\mathrm{LF}_{\mathrm{N}}$ by showing that if only one $\mathrm{SO}_{3}{ }^{-}$, which is essentially not titratable, is introduced at most positions in $\mathrm{LF}_{\mathrm{N}}$ (through the reaction of an introduced cysteine residue at those positions with 2sulfonato-ethyl-methanethiosulfonate [MTS-ES]), LF $_{\mathrm{N}}$ translocation is drastically inhibited.

\section{MATERIALS AND METHODS}

\section{Protein Purification and Labeling with MTS Reagents} Wild-type (WT) PA (83 kD), its F427A mutant, LF $_{\mathrm{N}}$ (residues 1-263 of LF, containing the N-terminal Novagen $\mathrm{His}_{6}$-tag), and its cysteine mutants (Fig. 1) were expressed recombinantly and purified as described previously (Krantz et al., 2004, 2005; Pimental et al., 2004; Zhang et al., 2004b). The heptameric prepore form of $\mathrm{PA}_{63}$ was prepared by nicking $\mathrm{PA}_{83}$ with trypsin and purifying the $\mathrm{PA}_{63}$ heptamer from the smaller 20-kD fragment using anionexchange chromatography (Cunningham et al., 2002). The MTSlabeling reaction of $\mathrm{LF}_{\mathrm{N}}$ cysteine mutants was performed by incubation of $100 \mu \mathrm{l} \mathrm{LF}_{\mathrm{N}}(2 \mathrm{mg} / \mathrm{ml})$ with $3 \mu \mathrm{l}$ of MTS reagents $(20 \mu \mathrm{g} / \mu \mathrm{l}$; Toronto Research Chemicals) for $30 \mathrm{~min}$ at room temperature in degassed $150 \mathrm{mM} \mathrm{NaCl}$ and $20 \mathrm{mM} \mathrm{NaPO}_{4}, \mathrm{pH} 7.2$. The reaction was stopped by dialyzing out the MTS reagents at $4^{\circ} \mathrm{C}$. To confirm that virtually all of the protein was labeled, MTSreacted and unreacted protein were incubated with $600 \mu \mathrm{M}$ maleimide 5,000 polyethylene-glycol (PEG; Sigma-Aldrich) for $30 \mathrm{~min}$ at $30^{\circ} \mathrm{C}$ and then run on an SDS non-reducing acrylamide gel. The unreacted protein suffers a shift on the gel, whereas the MTS-reacted $\mathrm{LF}_{\mathrm{N}}$ is unaffected (Fig. 2); WT LF $\mathrm{N}_{\mathrm{N}}$, which has no native cysteines, is also unaffected (not depicted).

\section{Planar Lipid Bilayers}

Bilayers were formed by the brush technique (Mueller et al., 1963) across a $350-\mu \mathrm{m}$ diameter aperture in a Teflon partition. Membranes separated two compartments of $3.5 \mathrm{ml}$ containing symmetric buffered solutions of $100 \mathrm{mM} \mathrm{KCl}, 5 \mathrm{mM}$ potassium succinate, and $1 \mathrm{mM}$ EDTA, $\mathrm{pH} 5.5$, which could be stirred by small magnetic bars. Agar salt bridges $(3 \mathrm{M} \mathrm{KCl}, 3 \%$ agar) linked $\mathrm{Ag} / \mathrm{AgCl}$ electrodes in saturated $\mathrm{KCl}$ baths to the cis and trans compart- ments. The membrane-forming solution was 3\% diphytanoylphosphatidylcholine (Avanti Polar Lipids, Inc.) in $n$-decane, and membrane formation was monitored both visually and by capacitance $(\sim 500 \mathrm{pF})$. All experiments were performed under voltage clamp conditions with a Bilayer Clamp BC-525C (Warner Instruments). Voltages are those of the cis solution (to which protein was added) with respect to the trans solution, which was held at virtual ground. Current responses were filtered at $1 \mathrm{kHz}$ by a lowpass eight-pole Bessel filter (Warner Instruments), recorded by computer via an analogue-to-digital converter (NI USB-6211; National Instruments) at $20 \mathrm{~Hz}$, using IGOR NIDAQ Tools MX 1.0 and IGOR 6.0.3.1 (WaveMetrics Inc.), and confirmed by a chart recorder (DMP-4B Physiograph; Narco Bio-Systems Inc.).

\section{$\left(\mathrm{PA}_{63}\right)_{7}$ Channel Formation, $\mathrm{LF}_{\mathrm{N}}$ Conductance Block,} and Translocation

After membrane formation, $\mathrm{PA}_{63}$ prepore heptamer was added to the cis compartment (to a final concentration of $\sim 1 \mathrm{ng} / \mathrm{ml}[\sim 2$ $\mathrm{pM}]$ ), which was held at a $\Delta \psi$ of $+20 \mathrm{mV}$ with respect to the trans compartment. After the conductance consequent to $\left(\mathrm{PA}_{63}\right)_{7}$ channel formation had reached a more-or-less constant level, $\mathrm{LF}_{\mathrm{N}}$ was added to the cis compartment (final concentration, $\sim 3 \mathrm{nM}$ ). The progress of $\mathrm{LF}_{\mathrm{N}}$ binding to $\left(\mathrm{PA}_{63}\right)_{7}$ channels and blocking them was monitored by the continuous fall of conductance. In most experiments, $>95 \%$ of the conductance was blocked by $\mathrm{LF}_{\mathrm{N}}$ at $+20 \mathrm{mV}$ before translocation experiments were begun. After $\mathrm{LF}_{\mathrm{N}}$ conductance block of $\left(\mathrm{PA}_{63}\right)_{7}$ channels was complete, excess ligand was removed from the cis compartment by perfusion, using a BPS-2 Bilayer Perfusion System (Warner Instruments) coupled to a peristaltic pump (Buchler) at a rate of $10 \mathrm{ml} / \mathrm{min}$. The exchange of 10 volumes was accomplished in three and a half minutes, while $\Delta \psi$ was held constant at $+20 \mathrm{mV}$. After this, $\Delta \psi$ was stepped to $+55 \mathrm{mV}$, and the rate of $\mathrm{LF}_{\mathrm{N}}$ translocation was determined, as reflected in the rate of conductance rise caused by $L_{N}$ traversing the channel and exiting into the trans solution.

In Figs. 3-6, what is plotted is the normalized conductance versus time. With the exception of the MTS-ES-reacted LF N $_{\mathrm{N}}$ cysteine mutants that never reached a constant value, conductances were normalized to the level obtained after unblocking at $+55 \mathrm{mV}$ was completed. In general, this conductance level was $\geq 90 \%$ of the conductance level before blocking by $\mathrm{LF}_{\mathrm{N}}$. For the MTS-ESreacted $L_{\mathrm{N}}$ mutants, after the $55 \mathrm{mV}$ was applied for the length of time indicated in the figures, the voltage was stepped for $30 \mathrm{~s}$ to $-80 \mathrm{mV}$, and then back to $+20 \mathrm{mV}$. Negative voltages drive $\mathrm{LF}_{\mathrm{N}}$ out of the channel back to the cis side, so that the conductance immediately obtained at $+20 \mathrm{mV}$ (before the slow reblocking of the channels by still-attached $L_{\mathrm{N}}$ ) represents that of unblocked channels. Conductances were normalized to this level, which was $\geq 90 \%$ of the conductance level before blocking by $\mathrm{LF}_{\mathrm{N}}$.
1

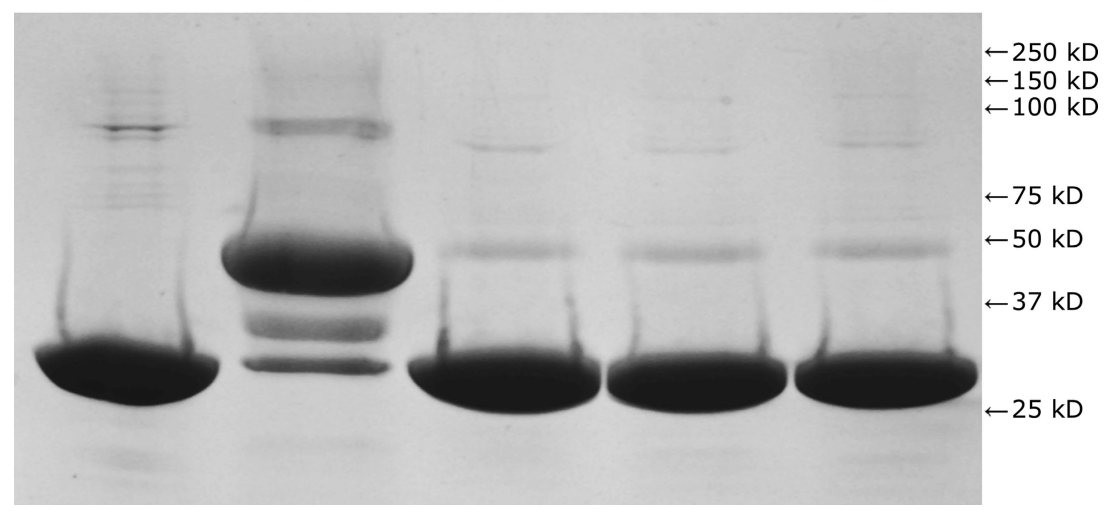

Figure 2. Example of an SDS non-reducing acrylamide gel of an $\mathrm{LF}_{\mathrm{N}}$ cysteine mutant (I77C) reacted with MTS reagents, followed by incubation with maleimide 5,000 PEG. Lane 1, I77C; lane 2, I77C plus maleimide PEG; lane 3, I77C reacted with MTS-ES, followed by maleimide PEG; lane 4, I77C reacted with MTSET, followed by maleimide PEG; lane 5, I77C reacted with MTS-ACE, followed by maleimide PEG. Note the gel shift in lane 2 caused by the reaction of the maleimide PEG with the cysteine on I77C; the virtual absence of any such shift in lanes 3-5 indicates that almost all the I77C had reacted with the MTS reagent. 

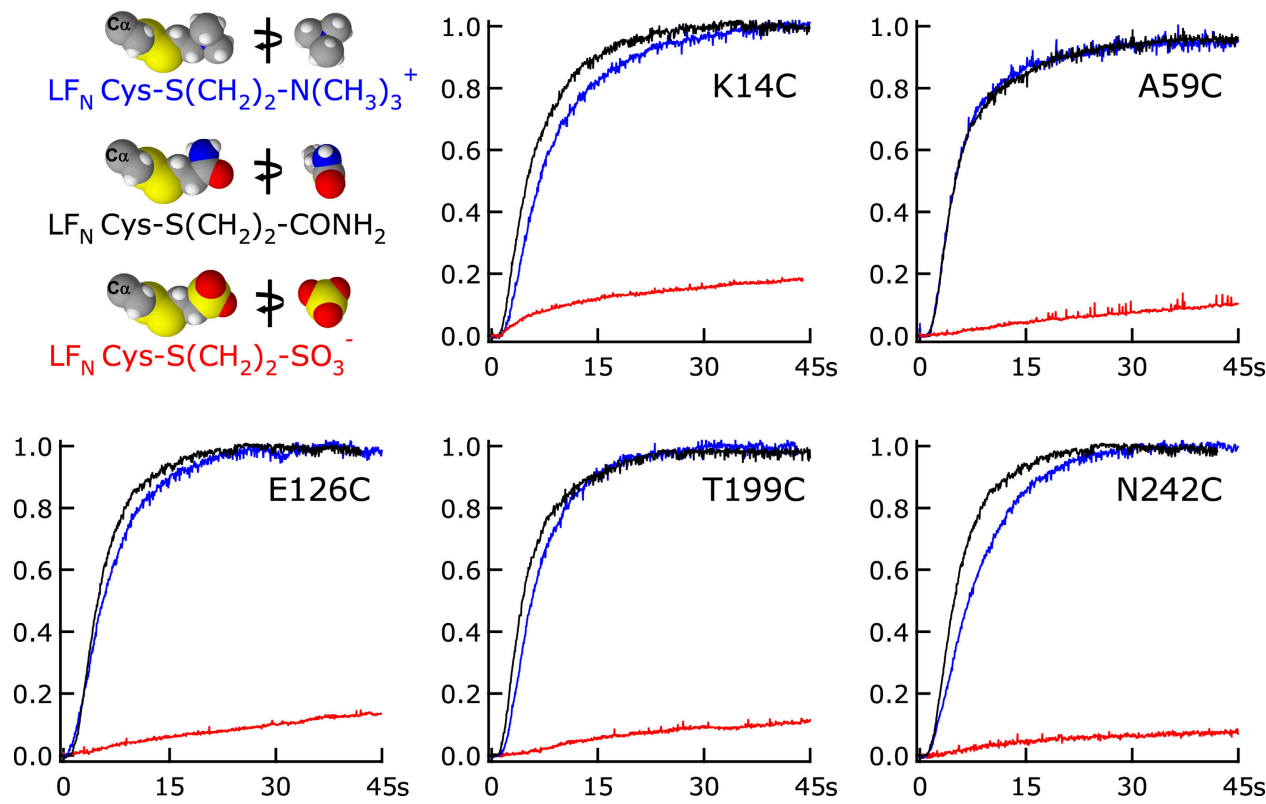

\section{RESULTS}

$\mathrm{LF}_{\mathrm{N}}$ translocation is driven by a gradient of the electrochemical potential of $\mathrm{H}^{+}$, which can be established by either applying a $\Delta \Psi$ or a $\Delta \mathrm{pH}$ (or both) across the membrane (see Finkelstein, 2009). Although pH-driven translocation is physiologically more relevant than voltage-driven translocation (Krantz et al., 2006), our concern here is strictly with the biophysics of voltage-driven translocation.

Effect of an Introduced $\mathrm{SO}_{3}{ }^{-}$on $\mathrm{LF}_{\mathrm{N}}$ Translocation

Despite $\mathrm{LF}_{\mathrm{N}}$ having a net negative charge of approximately -7 at $\mathrm{pH} 5.5$, it is driven through the $\left(\mathrm{PA}_{63}\right)_{7}$
Figure 3. The effect of introducing one $\mathrm{SO}_{3}{ }^{-}$(by reacting an $\mathrm{LF}_{\mathrm{N}}$ cysteine mutant with MTS-ES) on the translocation rate of $\mathrm{LF}_{\mathrm{N}}$. The panels show the normalized rise of conductance (a reflection of translocation of $\mathrm{LF}_{\mathrm{N}}$ through the $\left(\mathrm{PA}_{63}\right)_{7}$ channel) that occurred when, after the perfusion of the indicated MTS-reacted $\mathrm{LF}_{\mathrm{N}}$ cysteine mutant out of the cis compartment, the voltage was stepped from +20 to $+55 \mathrm{mV}$. Note the very slow translocation of the MTSES-reacted $\mathrm{LF}_{\mathrm{N}}$ (red). In contrast, the translocation rates of the MTSET-reacted (blue) and the MTSACE-reacted $\mathrm{LF}_{\mathrm{N}}$ (black) were essentially the same as that of WT $\mathrm{LF}_{\mathrm{N}}$ (which is not shown in the panels for clarity), with a half-time of $\sim 5 \mathrm{~s}$.

channel by cis-positive voltages (Zhang et al., 2004b). We have argued that this can occur because the carboxyls on the aspartates and glutamates of $\mathrm{LF}_{\mathrm{N}}$ are, for the most part, in their protonated form within the channel (Krantz et al., 2006), and that this is because the channel strongly disfavors the entry into it of negative charges (anions) (Finkelstein, 2009). If this is so, one might expect that the introduction into $\mathrm{LF}_{\mathrm{N}}$ of essentially non-titratable negative charges would have a detrimental effect on its translocation. And indeed, introducing only one $\mathrm{SO}_{3}{ }^{-}$at five arbitrarily chosen positions within its sequence had a profound effect on its rate of translocation. Namely, normally under

\section{$\mathrm{LF}_{\mathrm{N}}$ Cys-S $\left(\mathrm{CH}_{2}\right)_{2} \mathrm{CONH}_{2}$}

$\mathrm{LF}_{\mathrm{N}} \mathrm{Cys}-\mathrm{S}\left(\mathrm{CH}_{2}\right)_{2} \mathrm{SO}_{3}^{-}$

$\mathrm{LF}_{\mathrm{N}}$ Cys-S $\left(\mathrm{CH}_{2}\right)_{2} \mathrm{SO}_{3}{ }^{-}$, Lys $^{+}$

$\mathrm{LF}_{\mathrm{N}} \mathrm{Lys}^{+}$, Cys-S $\left(\mathrm{CH}_{2}\right)_{2} \mathrm{SO}_{3}^{-}$

$\mathrm{LF}_{\mathrm{N}}$ Lys $^{+}$, Cys-S $\left(\mathrm{CH}_{2}\right)_{2} \mathrm{SO}_{3}{ }^{-}$, Lys $^{+}$
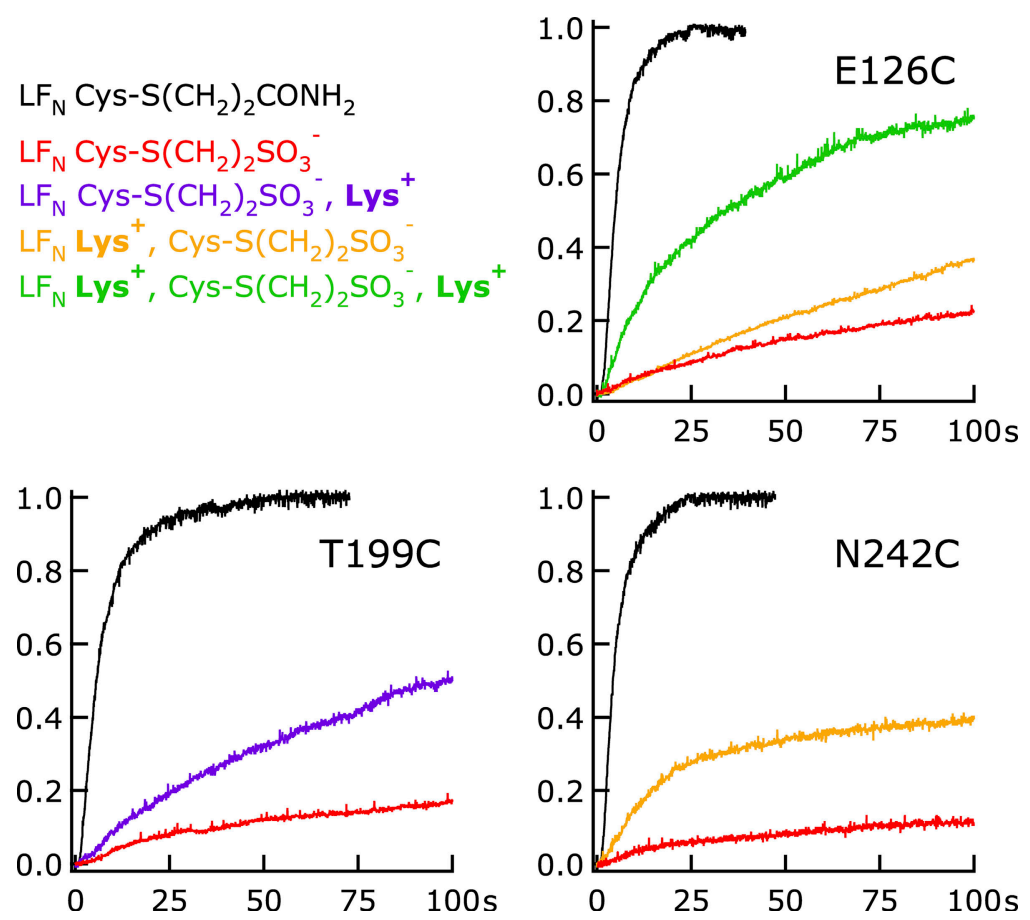

Figure 4. Partial recovery of the translocation rate of MTS-ES-reacted $\mathrm{LF}_{\mathrm{N}}$ (red) when positively charged lysines are flanking the introduced $\mathrm{SO}_{3}{ }^{-}$. The experiments were performed as described in Fig. 3. The rate of translocation of MTS-ACE-reacted LF $_{\mathrm{N}}$ E126C, T199C, and N242C (black) was the same as that of WT $\mathrm{LF}_{\mathrm{N}}$ and the unreacted lysine mutants (not depicted). Note that one lysine adjacent to the $\mathrm{SO}_{3}{ }^{-}$(orange in E126C and N242C, and purple in T199C) increased the rate of translocation, and two lysines, one on either side of the $\mathrm{SO}_{3}{ }^{-}$(green in E126C), produced an even greater increase in the rate of translocation, although still considerably short of the rate of translocation of WT $\mathrm{LF}_{\mathrm{N}}$. 
our experimental conditions (symmetric $\mathrm{pH}$ 5.5, $\Delta \Psi=$ $+55 \mathrm{mV}$ ) the translocation half-time of $\mathrm{LF}_{\mathrm{N}}$ (with the $\mathrm{N}$-terminal Novagen $\mathrm{His}_{6}$-tag) was $\sim 5$ s. However, after attaching a $\mathrm{S}-\left(\mathrm{CH}_{2}\right)_{2}-\mathrm{SO}_{3}{ }^{-}$at residue $\mathrm{K} 14 \mathrm{C}, \mathrm{A} 59 \mathrm{C}$, E126C, T199C, or N242C, we obtained $\leq 20 \%$ translocation even after 45 or $100 \mathrm{~s}$ (Figs. 3 and 4). (As expected, if $\mathrm{LF}_{\mathrm{N}}$ that had reacted with MTS-ES was subsequently treated with DTT to remove the $\mathrm{SO}_{3}{ }^{-}$, its translocation rate was restored to normal [not depicted].) This slow translocation time is most certainly a consequence of the introduced negative charge on $\mathrm{SO}_{3}{ }^{-}$, because attaching the similarly sized groups $\mathrm{S}-\left(\mathrm{CH}_{2}\right)_{2}-\mathrm{CONH}_{2}$ or $\mathrm{S}-\left(\mathrm{CH}_{2}\right)_{2}-\mathrm{N}\left(\mathrm{CH}_{3}\right)_{3}{ }^{+}$(by reacting with 2-aminocarbonylethyl-methanethiosulfonate [MTS-ACE] or 2-trimethylammonium-ethyl-methanethiosulfonate [MTS-ET], respectively) had virtually no effect on the translocation rate (Fig. 3).

In support of this "electrostatic" mechanism of translocation inhibition, we found that introducing one positive charge $\left(\mathrm{Lys}^{+}\right.$) adjacent to the $\mathrm{SO}_{3}{ }^{-}$-bearing cysteine residue at position 126, 199, or 242 increased the rate of translocation, and introducing two positive charges $\left(\mathrm{Lys}^{+}\right.$) flanking the $\mathrm{SO}_{3}{ }^{-}$at 126 (one at residue 125 and one at residue 127) further increased the rate of translocation (Fig. 4). Interestingly, the electrostatic barrier to $\mathrm{SO}_{3}{ }^{-}$entry into the channel is so large that even with positively charged lysines flanking the $\mathrm{SO}_{3}{ }^{-}$at residue 126 , the half-time was considerably slower than that of WT (36 instead of 5 s; Fig. 4).

\section{Exceptions}

Whereas introducing an $\mathrm{SO}_{3}{ }^{-}$at most positions in $\mathrm{LF}_{\mathrm{N}}$ drastically slowed translocation, we found two excep- tions to this: introducing $\mathrm{SO}_{3}{ }^{-}$at either the $\mathrm{C}$ terminus (residue 263) or the $\mathrm{N}$ terminus (residue 1) had no effect on the translocation rate (Fig. 5). One can rationalize the former by saying that unlike an interior residue that is followed by another residue, the C-terminal residue is followed by water, which via its higher dielectric constant reduces the electrostatic barrier to entry of the $\mathrm{SO}_{3}{ }^{-}$into the channel. One cannot, however, make the same argument for the N-terminal residue 1 and say that it is preceded by water, because our experiments were done with the 20-residue $\mathrm{His}_{6}$-tag attached at the $\mathrm{N}$ terminus. Thus, residue 1 is as much an interior residue as $14,59,126,199$, and 242, which, when reacted with MTSES, had a profound effect on translocation (Fig. 3).

Sequence gazing reveals that the neighborhood of residue 1 differs from that of the other residues we had examined in two respects: (1) it is followed by two glycines, and (2) there are positively charged residues (histidines) nearby on either side of it (at positions -2 and +4) (Fig. 1). Either one of these features could account for the failure of the introduced $\mathrm{SO}_{3}{ }^{-}$at position 1 to significantly slow translocation. Thus, because of their small size, the glycines could leave space for water to follow the residue; alternatively, the nearby charged residues could provide electrostatic shielding of the $\mathrm{SO}_{3}{ }^{-}$, just as was done by the introduced lysines on either side of residue 126 (Fig. 4). A similar situation exists in the neighborhood of residue 77; namely, it too is followed by two glycines and has nearby positively charged residues (in this case lysines) on either side of it (at positions 75 and 80) at exactly the same distances as exist for residue 1 . We therefore examined this position and found that if residue 77 was mutated to a cysteine and

$$
\begin{aligned}
& \mathrm{LF}_{\mathrm{N}} \text { Cys-S }\left(\mathrm{CH}_{2}\right)_{2} \mathrm{~N}\left(\mathrm{CH}_{3}\right)_{3}{ }^{+} \\
& \mathrm{LF}_{\mathrm{N}} \text { Cys-S }\left(\mathrm{CH}_{2}\right)_{2} \mathrm{CONH}_{2} \\
& \mathrm{LF}_{\mathrm{N}} \text { Cys-S }\left(\mathrm{CH}_{2}\right)_{2} \mathrm{SO}_{3}^{-} \\
& \mathrm{LF}_{\mathrm{N}} \mathrm{K} 75 \mathrm{E}, \mathrm{Cys}-\mathrm{S}\left(\mathrm{CH}_{2}\right)_{2} \mathrm{SO}_{3}{ }^{-}, \mathrm{K} 80 \mathrm{E}
\end{aligned}
$$

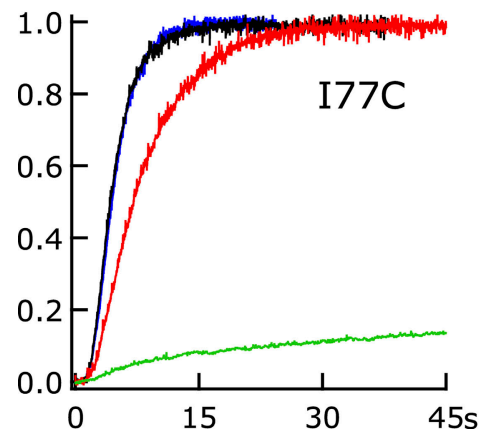

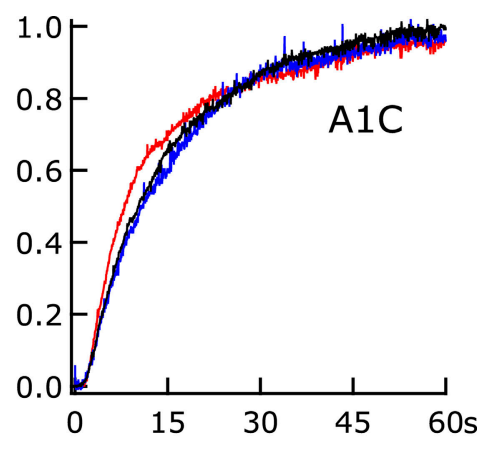

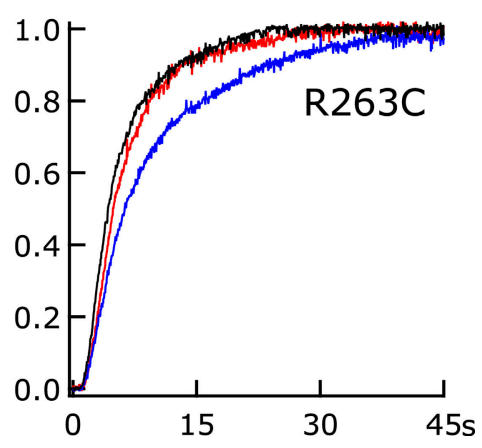

Figure 5. Introducing an $\mathrm{SO}_{3}{ }^{-}$at residues 1, 77, or 263 (by reacting the corresponding $\mathrm{LF}_{\mathrm{N}}$ cysteine mutant with MTS-ES; red) had very little or no effect on the translocation rate of $\mathrm{LF}_{\mathrm{N}}$. The experiments were performed as described in Fig. 3. Note that if the nearby lysines were mutated to glutamates at positions $\mathrm{K} 75 \mathrm{E}$ and $\mathrm{K} 80 \mathrm{E}$ (green), an $\mathrm{SO}_{3}{ }^{-}$at position 77 greatly retarded $\mathrm{LF}_{\mathrm{N}}$ translocation as in Fig. 4. The glutamate mutations alone did not affect the translocation rate (not depicted). (For unknown reasons, the rate of translocation of $\mathrm{LF}_{\mathrm{N}} \mathrm{A} 1 \mathrm{C}$ reacted with MTS-ES, MTSET, or MTS-ACE [half-time of $10 \mathrm{~s}$ ] was half that of WT $\mathrm{LF}_{\mathrm{N}}$ [half-time of $\left.5 \mathrm{~s}\right]$.) 
then reacted with MTS-ES, the translocation rate was barely affected (Fig. 5). It appears that of the two possible factors that we have speculated could be the cause of this, the two glycines or electrostatic shielding, it is the latter that accounts for this at position 77 , because when the lysines at positions 75 and 80 were mutated to glutamates, the introduction of an $\mathrm{SO}_{3}{ }^{-}$at position 77 now severely slowed translocation (Fig. 5). Unfortunately, mutating the histidines at positions -2 and +4 to aspartates had no effect on the translocation of the MTS-ES-reacted cysteine at position 1 (not depicted). Thus, why an $\mathrm{SO}_{3}{ }^{-}$at position 1 does not slow translocation remains an unexplained exception.

\section{A Site of Negative Charge Exclusion from the Channel}

Where within the channel is the negative charge exclusion of $\mathrm{SO}_{3}{ }^{-}$occurring? The $\left(\mathrm{PA}_{63}\right)_{7}$ channel is a mushroom-like structure with a long stem and a cap that contains the binding site for $\mathrm{LF}_{\mathrm{N}}$ (Fig. $6 \mathrm{~B}$ ) (Krantz et al., 2005; Katayama et al., 2008). Near the junction of the cap with the stem lies residue F427, which forms a ring of seven phenylalanines that plays an important role in protein translocation, and which we have dubbed the $\Phi$-clamp (Krantz et al., 2005). If the phenylalanines were mutated to alanines, protein translocation was compromised (Krantz et al., 2005, 2006). When F427 was mutated to an alanine, the rate of voltage-driven translocation decreased by about a factor of three, but, strikingly, the rate of translocation of $\mathrm{LF}_{\mathrm{N}}$ with an attached $\mathrm{SO}_{3}{ }^{-}$enormously increased. (A much larger decrease occurs in the rate of translocation driven by a $\mathrm{pH}$ gradient [Krantz et al., 2005, 2006] and is probably a consequence of the creation of a leakage pathway for protons, thereby compromising the $\Delta \mathrm{pH}$ across the $\Phi$-clamp.) This effect of the alanine mutation is clearly seen in Fig. 6 A for $\mathrm{LF}_{\mathrm{N}} \mathrm{A} 59 \mathrm{C}$; a similar effect was seen for the other residue tested, $\mathrm{LF}_{\mathrm{N}} \mathrm{N} 242 \mathrm{C}$ (not depicted). With either WT $\mathrm{LF}_{\mathrm{N}}$ or the neutral $\left(\mathrm{CH}_{2}\right)_{2} \mathrm{CONH}_{2}$ attached to the $\mathrm{LF}_{\mathrm{N}} \mathrm{A} 59 \mathrm{C}$ cysteine, the half-time of translocation $($ at $+55 \mathrm{mV}$ ) increased from $\sim 5$ to $\sim 15 \mathrm{~s}$, whereas with $\mathrm{SO}_{3}{ }^{-}$attached to the cysteine, the halftime decreased from a value $>200$ to $\sim 30$ s. Thus, the mutation of F427 to an alanine has almost completely removed a barrier to $\mathrm{SO}_{3}{ }^{-}$translocation. The effect of the $\Phi$-clamp on anion entry into the channel was also manifested in the channel becoming less selective for

$$
\begin{array}{r}
\text { A WT }\left(\mathrm{PA}_{63}\right)_{7} \text { channel }\left\{\begin{array}{l}
\mathrm{LF} \text { Cys-S }\left(\mathrm{CH}_{2}\right)_{2} \mathrm{CONH}_{2} \\
L F_{\mathrm{N}} \text { Cys-S }\left(\mathrm{CH}_{2}\right)_{2} \mathrm{SO}_{3}{ }^{-}
\end{array}\right. \\
\left(\mathrm{PA}_{63} \mathrm{~F} 427 \mathrm{~A}\right)_{7} \text { channel }\left\{\begin{array}{l}
L F_{\mathrm{N}} \text { Cys-S }\left(\mathrm{CH}_{2}\right)_{2} \mathrm{CONH}_{2} \\
L F_{\mathrm{N}} \text { Cys-S }\left(\mathrm{CH}_{2}\right)_{2} \mathrm{SO}_{3}{ }^{-}
\end{array}\right.
\end{array}
$$

$\mathrm{Arg}^{+} / \mathrm{His}^{+} / \mathrm{Lys}^{+}$
$\mathrm{H}^{+}$
$\mathrm{Asp}^{0} / \mathrm{Glu}^{0}$
$\mathrm{Asp}^{-} / \mathrm{Glu}^{-}$
$\mathrm{Cys}-\mathrm{S}\left(\mathrm{CH}_{2}\right)_{2} \mathrm{SO}_{3}$

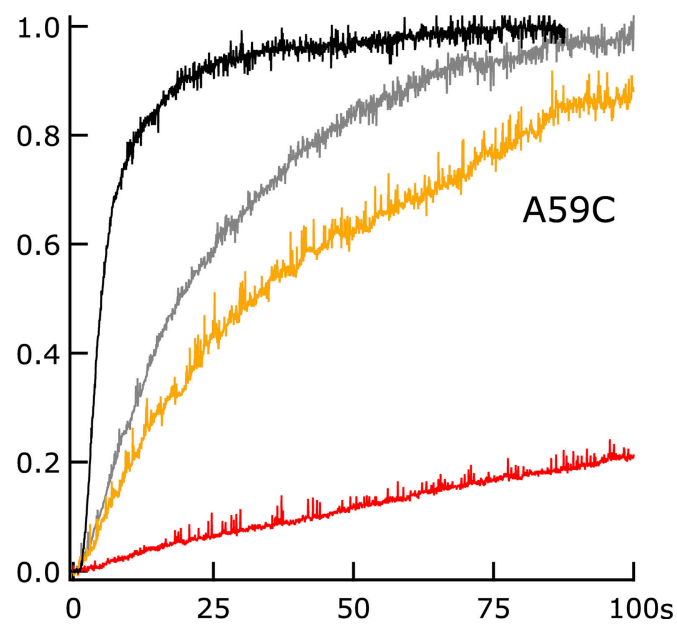

B

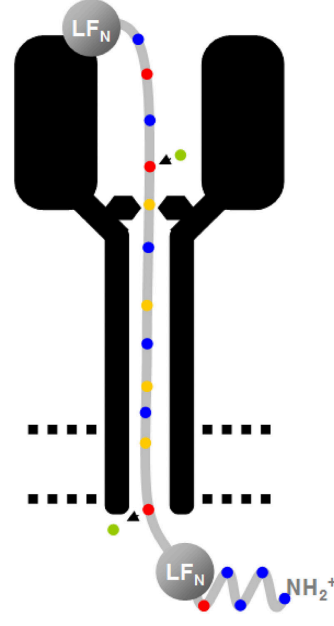

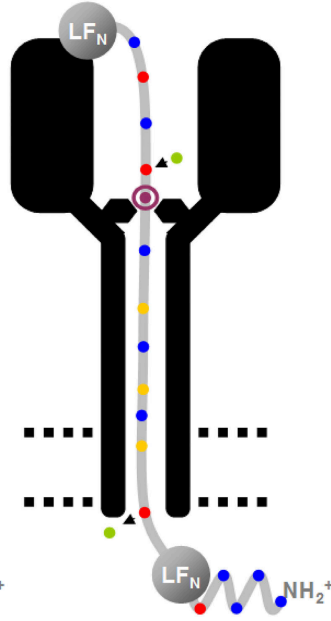

Figure 6. The effect of replacing phenylalanine with alanine at residue 427 of $\mathrm{PA}_{63}$ on the rate of translocation of $\mathrm{LF}_{\mathrm{N}}$. (A) The experiments were performed as described in Fig. 3. For the WT channel, as shown in Fig. 3 and reproduced here, the introduction of an $\mathrm{SO}_{3}{ }^{-}$ at residue 59 (red) drastically reduced the rate of $\mathrm{LF}_{\mathrm{N}}$ translocation from that of MTS-ACE-reacted $\mathrm{LF}_{\mathrm{N}}$ (black), which was the same as that of $\mathrm{WT} \mathrm{LF}_{\mathrm{N}}$ (not depicted). Mutating the phenylalanine at residue 427 to alanine in the $\left(\mathrm{PA}_{63}\right)_{7}$ channel dramatically increased the rate of translocation of $\mathrm{LF}_{\mathrm{N}}$ with an attached $\mathrm{SO}_{3}^{-}$(orange) and decreased the rate of translocation of MTS-ACE-reacted LF $($gray), which was the same as that of WT LF (not depicted). (B) Cartoon of the $\left(\mathrm{PA}_{63}\right)_{7}$ channel with $\mathrm{LF}_{\mathrm{N}}$ being translocated through it. The constriction near the junction of the vestibule with the stem is the $\Phi$-clamp, which is formed by seven F427s. We envision that for negatively charged residues (aspartates or glutamates) on $\mathrm{LF}_{\mathrm{N}}$ to get past the $\Phi$-clamp, they must be neutralized; that is, they pick up protons from the cis solution. This proton is subsequently discharged into the trans solution after the residue has traversed the channel. If a nontitratable $\mathrm{SO}_{3}{ }^{-}$is introduced into $\mathrm{LF}_{\mathrm{N}}$, it is retarded at the $\Phi$-clamp. Mutation of $\mathrm{F} 427$ to alanine alters the constriction and now more readily allows a negatively charged group such as $\mathrm{SO}_{3}{ }^{-}$to get past it. 
$\mathrm{K}^{+}$over $\mathrm{Cl}^{-}$. We see in Fig. 7 that the $\left(\mathrm{PA}_{63} \mathrm{~F} 427 \mathrm{~A}\right)_{7}$ channel, although still cation selective, is less so than is the WT channel.

\section{DISCUSSION}

Because $\mathrm{LF}_{\mathrm{N}}$ translocation from the cis to the trans solution through $\left(\mathrm{PA}_{63}\right)_{7}$ channels is driven by cis-positive voltages, even though $L_{\mathrm{N}}$ bears a net negative charge, we have argued that $\mathrm{LF}_{\mathrm{N}}$ 's aspartates and glutamates must be transported in their protonated (neutralized) form (see Krantz et al., 2006; Finkelstein, 2009). That is, negatively charged residues are largely excluded at some point from entering the channel. The experiments reported here support this argument in that (with specific exceptions discussed below) the intro-

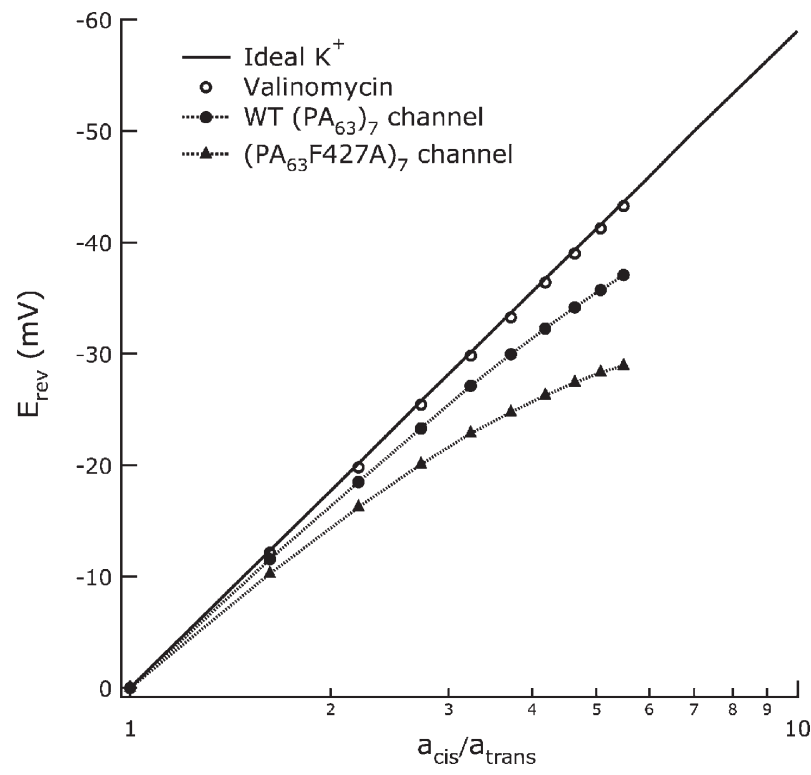

Figure 7. The effect of mutating F427 to an alanine on the ion selectivity of the $\left(\mathrm{PA}_{63}\right)_{7}$ channel. The experiments were started with the membrane (diphytanoyl-phosphatidylcholine) separating symmetric solutions of $100 \mathrm{mM} \mathrm{KCl}, 5 \mathrm{mM}$ potassium succinate, and $1 \mathrm{mM}$ EDTA, $\mathrm{pH}$ 5.5. After treating the membrane with either valinomycin $(0.2 \mu \mathrm{g} / \mathrm{ml})$, WT $\left(\mathrm{PA}_{63}\right)_{7}$, or $\left(\mathrm{PA}_{63} \mathrm{~F} 427 \mathrm{~A}\right)_{7}, \mathrm{KCl}$ was added in steps to the cis solution, and for each step the reversal potential $\left(\mathrm{E}_{\mathrm{rev}}\right)$ was measured. Plotted in the figure is $\mathrm{E}_{\mathrm{rev}}$ versus the activity ratio of $\mathrm{KCl}\left(\mathrm{a}_{\text {cis }} / \mathrm{a}_{\text {trans }}\right)$. (Activity coefficients were obtained from Appendix 8.10, Table II in Robinson and Stokes [1965], where we took the $\mathrm{KCl}$ concentration to be equal to the $\mathrm{K}^{+}$concentration. Approximately $10 \mathrm{mM}$ of $\mathrm{K}^{+}$was contributed by K-succinate and K-EDTA.) We see in the figure that, as expected, the valinomycin-treated membrane (open circles) displayed ideal $\mathrm{K}^{+}$selectivity (continuous line). The selectivity of the WT $\left(\mathrm{PA}_{63}\right)_{7}$ treated membrane (filled circles) deviated somewhat from ideal cation selectivity, and that of the $\left(\mathrm{PA}_{63} \mathrm{~F} 427 \mathrm{~A}\right)_{7}$-treated membrane (filled triangles) deviated even more so; that is, it was more permeable to $\mathrm{Cl}^{-}$than was the WT channel. The dotted lines are drawn to connect the points. (Applying inappropriately, as usual, the Goldman-Hodgkin-Katz equation to the data, we calculate that $\mathrm{P}_{\mathrm{K}} / \mathrm{P}_{\mathrm{Cl}}$ is 21 and 7.6 for the WT $\left(\mathrm{PA}_{63}\right)_{7}$ and $\left(\mathrm{PA}_{63} \mathrm{~F} 427 \mathrm{~A}\right)_{7}$ channels, respectively.) duction (by reacting single-site cysteine mutants with MTS-ES) of only one, essentially non-titratable negative charge $\left(\mathrm{SO}_{3}{ }^{-}\right)$at arbitrarily chosen positions in $\mathrm{LF}_{\mathrm{N}}$ drastically reduced the rate of its translocation (Fig. 3). The electrostatic basis for this exclusion of $\mathrm{SO}_{3}{ }^{-}$is reinforced by our observation that it could be partially ameliorated by the placement of positive charges (lysines) adjacent to it in the amino acid sequence (Fig. 4).

The exceptions to the inhibitory effect on $\mathrm{LF}_{\mathrm{N}}$ translocation by an $\mathrm{SO}_{3}{ }^{-}$attached to the $\mathrm{C}$ terminus (residue 263 ) or to residue 77 can be interpreted in terms of the electrostatic forces acting to exclude $\mathrm{SO}_{3}{ }^{-}$from the channel. Thus, the failure of an $\mathrm{SO}_{3}{ }^{-}$at the $\mathrm{C}$ terminus to reduce the translocation rate can be attributed to the water molecules surrounding $\mathrm{SO}_{3}{ }^{-}$at this position, which, because of their high dielectric constant, attenuate the electrostatic repulsive forces acting to exclude $\mathrm{SO}_{3}{ }^{-}$from the channel. An interior $\mathrm{SO}_{3}{ }^{-}$-attached residue will in general not have sufficient space around it to admit many water molecules. The failure of an $\mathrm{SO}_{3}{ }^{-}$at residue 77 to reduce translocation can be attributed to electrostatic shielding of its charge by nearby positively charged lysines at positions 75 and 80. Indeed, when they were mutated to glutamates, the introduction of an $\mathrm{SO}_{3}{ }^{-}$at position 77 drastically slowed translocation (Fig. 5). This result, obtained by removing positive charges nearby the $\mathrm{SO}_{3}{ }^{-}$and thereby slowing $\mathrm{LF}_{\mathrm{N}}$ translocation, nicely complements the results obtained by adding positive charges nearby the $\mathrm{SO}_{3}{ }^{-}$, and thereby accelerating $\mathrm{LF}_{\mathrm{N}}$ translocation (Fig. 4). The one exception that remains unexplained is why the introduction of an $\mathrm{SO}_{3}{ }^{-}$at position 1 (which is actually an interior residue because it is preceded by a 20 -residue $\mathrm{His}_{6}$-tag) did not retard translocation.

We also identified the $\Phi$-clamp as a significant factor in the exclusion of $\mathrm{SO}_{3}{ }^{-}$from the channel. Thus, the $\left(\mathrm{PA}_{63} \mathrm{~F} 427 \mathrm{~A}\right)_{7}$ channel translocated MTS-ES-reacted LF${ }_{N} \mathrm{~A} 59 \mathrm{C}$ at least an order of magnitude faster than did the $\mathrm{WT}\left(\mathrm{PA}_{63}\right)_{7}$ channel (Fig. $6 \mathrm{~A}$ ), and its selectivity for $\mathrm{K}^{+}$ over $\mathrm{Cl}^{-}$was diminished from that of the WT channel (Fig. 7). (The $\Phi$-clamp is not the only site that acts to exclude $\mathrm{Cl}^{-}$from the channel. One expects that the rings of negative charge within the channel created by residues D276, E302, E308, D315, D335, and E343 should participate in this process. And indeed, the triplemutant channel E302S/E308S/D315S was much less selective for $\mathrm{K}^{+}$over $\mathrm{Cl}^{-}$than was the $\mathrm{F} 427 \mathrm{~A}$ channel [unpublished data], and, as expected, $\mathrm{LF}_{\mathrm{N}}$ translocation was severely impaired [unpublished data].) Why the mutation of F427 to an alanine results in a channel that is less exclusionary of anions is not obvious. One possibility is that the mutation causes a repositioning further away from the entrance to the channel of the nearby negatively charged aspartates at positions 425 and 426 . It is interesting to note that this loss in anion exclusion is accompanied by a decrease in the translocation rate 
of WT $\mathrm{LF}_{\mathrm{N}}$ (Fig. $6 \mathrm{~A}$ ). This is to be expected, because insofar as ionized glutamates and aspartates on $\mathrm{LF}_{\mathrm{N}}$ are allowed to enter the channel, they will act to retard its (positive) voltage-driven translocation. At this time, it is not clear to what extent the slower voltage-driven translocation of $\mathrm{LF}_{\mathrm{N}}$ through the $\left(\mathrm{PA}_{63} \mathrm{~F} 427 \mathrm{~A}\right)_{7}$ channel is a consequence of its allowing negatively charged glutamates and aspartates to enter the channel, or to its effect on the unfolding of $\mathrm{LF}_{\mathrm{N}}$ (Krantz et al., 2005).

We thank Dr. Paul Kienker for the GHK calculations and insightful comments, and Dr. Myles Akabas for critically reading this paper.

This work was supported by National Institutes of Health grants GM-29210 (to A. Finkelstein) and AI-22021 (to R.J. Collier).

Lawrence G. Palmer served as editor.

Submitted: 25 November 2008

Accepted: 15 January 2009

\section{REFERENCES}

Benson, E.L., P.D. Huynh, A. Finkelstein, and R.J. Collier. 1998. Identification of residues lining the anthrax protective antigen channel. Biochemistry. 37:3941-3948.

Blaustein, R.O., and A. Finkelstein. 1990. Voltage-dependent block of anthrax toxin channels in planar phospholipid bilayer membranes by symmetric tetraalkylammonium ions. Effects on macroscopic conductance. J. Gen. Physiol. 96:905-919.

Blaustein, R.O., T.M. Koehler, R.J. Collier, and A. Finkelstein. 1989. Anthrax toxin: channel-forming activity of protective antigen in planar phospholipid bilayers. Proc. Natl. Acad. Sci. USA. 86:2209-2213.

Bragg, T.S., and D.L. Robertson. 1989. Nucleotide sequence and analysis of the lethal factor gene (lef) from Bacillus anthracis. Gene. $81: 45-54$.

Cunningham, K., D.B. Lacy, J. Mogridge, and R.J. Collier. 2002. Mapping the lethal factor and edema factor binding sites on oligomeric anthrax protective antigen. Proc. Natl. Acad. Sci. USA. 99:7049-7053.

Drum, C.L., S.Z. Yan, J. Bard, Y.Q. Shen, D. Lu, S. Soelaiman, Z. Grabarek, A. Bohm, and W.J. Tang. 2002. Structural basis for the activation of anthrax adenylyl cyclase exotoxin by calmodulin. Nature. 415:396-402.
Finkelstein, A. 2009. Proton-coupled protein transport through the anthrax toxin channel. Philos. Trans. R. Soc. Lond. B Biol. Sci. 364:209-215.

Katayama, H., B.E. Janowiak, M. Brzozowski, J. Juryck, S. Falke, E.P. Gogol, R.J. Collier, and M.T. Fisher. 2008. GroEL as a molecular scaffold for structural analysis of the anthrax toxin pore. Nat. Struct. Mol. Biol. 15:754-760.

Krantz, B.A., A.D. Trivedi, K. Cunningham, K.A. Christensen, and R.J. Collier. 2004. Acid-induced unfolding of the amino-terminal domains of the lethal and edema factors of anthrax toxin. J. Mol. Biol. 344:739-756.

Krantz, B.A., R.A. Melnyk, S. Zhang, S.J. Juris, D.B. Lacy, Z. Wu, A. Finkelstein, and R.J. Collier. 2005. A phenylalanine clamp catalyzes protein translocation through the anthrax toxin pore. Science. 309:777-781.

Krantz, B.A., A. Finkelstein, and R.J. Collier. 2006. Protein translocation through the anthrax toxin transmembrane pore is driven by a proton gradient. J. Mol. Biol. 355:968-979.

Mueller, P., D.O. Rudin, H.T. Tien, and W.C. Westcott. 1963. Methods for the formation of single bimolecular lipid membranes in aqueous solution. J. Phys. Chem. 67:534-335.

Nassi, S., R.J. Collier, and A. Finkelstein. 2002. $\mathrm{PA}_{63}$ channel of anthrax toxin: an extended beta-barrel. Biochemistry. 41:1445-1450.

Nguyen, T.L. 2004. Three-dimensional model of the pore form of anthrax protective antigen. Structure and biological implications. J. Biomol. Struct. Dyn. 22:253-265.

Pannifer, A.D., T.Y. Wong, R. Schwarzenbacher, M. Renatus, C. Petosa, J. Bienkowska, D.B. Lacy, R.J. Collier, S. Park, S.H. Leppla, et al. 2001. Crystal structure of the anthrax lethal factor. Nature. 414:229-233.

Pimental, R.A., K.A. Christensen, B.A. Krantz, and R.J. Collier. 2004. Anthrax toxin complexes: heptameric protective antigen can bind lethal factor and edema factor simultaneously. Biochem. Biophys. Res. Commun. 322:258-262.

Robinson, R.A., and R.H. Stokes. 1965. Electrolyte Solutions. Butterworth, London. 494 pp.

Young, J.A., and R.J. Collier. 2007. Anthrax toxin: receptor-binding, internalization, pore formation, and translocation. Annu. Rev. Biochem. 76:243-265.

Zhang, S., A. Finkelstein, and R.J. Collier. 2004a. Evidence that translocation of anthrax toxin's lethal factor is initiated by entry of its $\mathrm{N}$ terminus into the protective antigen channel. Proc. Natl. Acad. Sci. USA. 101:16756-16761.

Zhang, S., E. Udho, Z. Wu, R.J. Collier, and A. Finkelstein. 2004b. Protein translocation through anthrax toxin channels formed in planar lipid bilayers. Biophys. J. 87:3842-3849. 